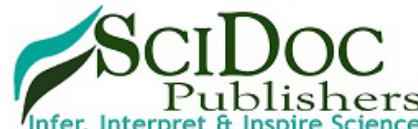

International Journal of Dentistry and Oral Science (IJDOS) ISSN: 2377-8075

\title{
Comparative Evaluation of Effect of White Noise, Nursery Rhymes and Movie Songs as Distraction Methods On Behaviour Of Children During Induction Of Nitrous Oxide Sedation In Pediatric Dentistry
}

Research Article

Janvi M Gandhi ${ }^{1 *}$, Subramanian $\mathrm{EMG}^{2}$

${ }^{1}$ Post Graduate student, Department of Pediatric and Preventive Dentistry, Saveetha Dental college and Hospitals, Saveetha Institute of Medical and Technical Sciences, Saveetha University, Chennai - 600077, India.

${ }^{2}$ Professor, Department ofPediatric and Preventive Dentistry, Saveetha Dental college and Hospitals, Saveetha Institute of Medical and Technical Sciences, Saveetha University, Chennai - 600077, India.

\section{Abstract}

Introduction: Audio distraction is a non-aversive distraction technique in which patients are made to listen to music or stories during a stressful procedure. Nitrous oxide sedation is used for patients who experience dental anxiety and fear but the induction process itself can be anxiety provoking due to the use of a nasal hood, hence use of different audio distraction techniques during nitrous oxide inhalation are compared in this study. It involves a combination of two basic behaviour guidance techniques namely audio distraction and nitrous oxide inhalation.

Materials and Methods: This study included children below 6 years of age and were divided randomly into 3 groups. Group A (10)- White noise, Group B (10)- Nursery rhymes and Group C (10)-Control group which had movie songs playing in the background.

Results: There was no statistical significance between the 3 audio distraction groups but it was found that the white noise group helped in rendering better treatment as the children could respond to the operator's instructions and listen to the soothing music at the same time.

Conclusion: Usage of white noise as a distraction method is a good option as it is soothing and acceptable by all children.

Keywords: Music; Distraction; Behaviour Guidance; Nitrous Oxide; Inhalation.

\section{Introduction}

Children are usually very anxious and uncooperative in the dental environment and this is a significant and common problem faced by pediatric dentists. Hence, pediatric dentists use distraction techniques to divert the children from what may be perceived as an unpleasant situation. The behaviors of the dentist plays an important role in behavior guidance of the pediatric patient. Nitrous oxide sedation in dental offices is used for patients who experience dental anxiety, fear, dental phobia and require long dental treatments but the induction process itself can be anxiety provoking as it involves the use of a nasal hood, hence use of different audio distraction techniques are compared in this study during nitrous oxide sedation. Audio distraction is a non-aversive distraction technique in which patients listen to music or stories during a stressful procedure. [1,2]. Non aversive techniques are effective and more acceptable by the parents [3]. This study involves a combination of two basic behaviour guidance techniques [1] namely audio distraction and nitrous oxide inhalation.

Nitrous oxide and oxygen is widely used for conscious sedation in dental offices. It can have benefits for patients who experience dental anxiety or are medically compromised [4]. The other behavior guidance technique used in this study is audio distraction using white noise and nursery rhymes. White noise has the same amplitude or intensity, throughout the audible frequency range (20 to 20,000 Hertz). White noise is so named because it's analogous to white light, which is a mixture of all visible wavelengths

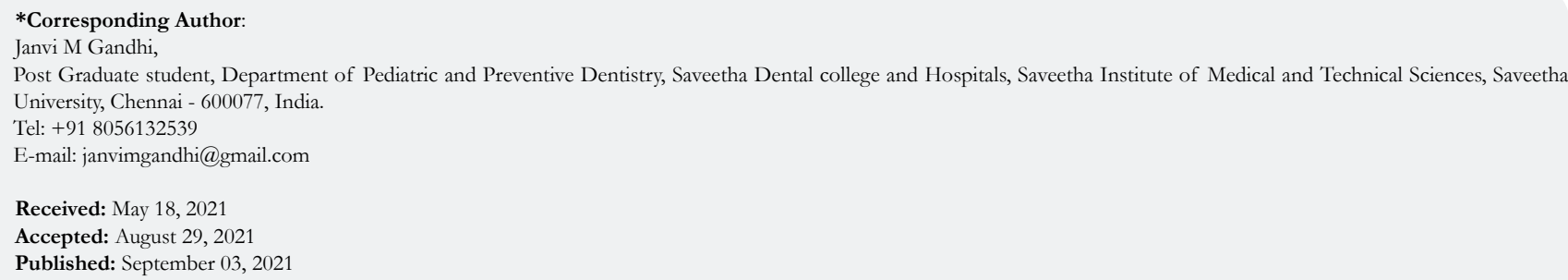

Citation: Janvi M Gandhi, Subramanian EMG. Comparative Evaluation of Effect of White Noise, Nursery Rhymes and Movie Songs as Distraction Methods On Behaviour Of Children During Induction Of Nitrous Oxide Sedation In Pediatric Dentistry Int J Dentistry Oral Sci. 2021;8(9):4209-4211. doi: http://dx.doi.org/10.19070/2377-8075-21000857

Copyright: Janvi M Gandhi ${ }^{\circ}$ 2021. This is an open-access article distributed under the terms of the Creative Commons Attribution License, which permits unrestricted use, distribution and reproduction in any medium, provided the original author and source are credited. 
of light. [5] Since children are unable to comprehend their preferred choice of music at this young age, usage of white noise as a distraction method is a good option as it is soothing and acceptable by all children.

No previous study done on the comparison of white noise and nursery rhymes on the behaviour of children during induction of nitrous oxide sedation. It is proved that integration of good behavioural techniques leads to better results and more efficient treatment. The null hypothesis is that there is no difference in behaviour of children after audio distraction methods during induction of nitrous oxide sedation. Aim of this study is to compare the effect of white noise and nursery rhymes on behaviour of children during induction of nitrous oxide sedation.

\section{Materials and Methods}

This study was done in a university setting and ethical approval was obtained from the institutional review board, Saveetha Institute of Medical and Technical sciences. The study population was children 6 years of age and below who underwent nitrous oxide sedation for any dental treatment. This study involved one investigator and the sample size of 15 was divided equally into 3 groups.

- Group 1 (5)- White noise

- Group 2 (5)- Nursery rhymes

- Group 3 (5)- Control group which had movie songs playing in the background.

\section{Assessment of Behaviour}

Venham's behaviour rating scale (Figure 1) is used in this study. Behaviour of the child was noted at the start of the induction process of nitrous oxide and 1 minute after induction. The children were randomly divided into one of the three groups and audio distraction was done for 1 minute only during the induction process of nitrous oxide sedation (Figure 2).

The inclusion criteria was any anxious child below 6 years who required to undergo dental treatment under nitrous oxide sedation. Exclusion criteria was cooperative children who underwent dental treatment without sedation. The Case sheet was verified by an external examiner and this study was found to have internal validity.

\section{Statistical Analysis}

Data was collected and tabulated using google sheets and verified by an external examiner. Coding done in google sheets and Imported to IBM SPSS V 23.0 software, IBM corporation, NY, USA.

- Independent variables- Distraction techniques and gender

- Dependent variables- Behaviour of children

Kruskallwallis test and Chi-square tests were done to statistically analyse the intergroup comparison between the three audio distraction groups in this study. Level of significance was set at 0.05 .

\section{Results}

Venham'sbehavior rating scale was used to assess behavior of the child during the nitrous oxide induction process in this study. A total of 15 children were included ( 7 boys, 8 girls) which belonged to the age group of $4-6$ years. $70 \%$ of the children in the white noise group (Group 1) showed a behavior rating of 1 . The other groups had higher ratings of 2 on the Venham'sbehavior rating scale. Although there wasn't much of a difference in the ratings of Group 1 and 2.

Based on the statistical analysis, the intergroup comparison of

Figure 1. Venham's behavior rating scale.

\begin{tabular}{|l|l|}
\hline Rating & Definition (behavioral rating scale) \\
\hline 0. & Total cooperation, best possible working conditions, no crying or physical protest \\
\hline 1. & $\begin{array}{l}\text { Mild, soft verbal protest or (quite) crying as a signal of discomfort, but does not obstruct } \\
\text { progress. Appropriate behavior for procedure }\end{array}$ \\
\hline 2. & $\begin{array}{l}\text { Protest more prominent. Both crying and hand signals. May move head around making it } \\
\text { hard to administer treatment. Protest more distracting and troublesome. However, child } \\
\text { still complies with request to cooperate }\end{array}$ \\
\hline 3. & $\begin{array}{l}\text { Protest presents real problem to dentist. Complies with demands reluctantly, requiring } \\
\text { extra effort by dentist. Body movement }\end{array}$ \\
\hline 4. & $\begin{array}{l}\text { Protest disrupts procedure, requires that all of the dentist attention be directed toward } \\
\text { the child behavior. Compliance eventuallyachieved after considerable effort by dentist, } \\
\text { but without much actual physical restraints. More prominent body movement }\end{array}$ \\
\hline 5. & \begin{tabular}{l} 
General protest, no compliance or cooperation. Physical restraint is required \\
\hline
\end{tabular}
\end{tabular}

Figure 2. White noise being played as audio distraction during nitrous oxide inhalation.

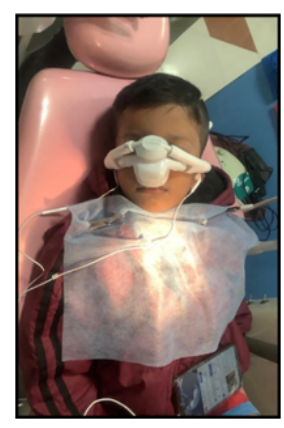


behavior of the child during audio distraction was not statistically signifcantamoung the three groups. ( $\mathrm{p}$ value $>0.05$ ).

\section{Discussion}

This study was done to analyse the effect of different audio distraction methods like white noise and nursery rhymes during the induction process of nitrous oxide sedation. The results of this study indicate that audio distraction did result in change of behaviour of the anxious children undergoing conscious sedation for pediatric dental treatment but the reduction in behavior level was not significant.

These results were consistent with several previous studies on audio distraction techniques $[6,2]$ but these studies evaluated both anxiety and behavior in children undergoing audio distraction. The present study exclusively assessed the reduction in disruptive behavior.

In contrast, these results were not in agreement with certain other studies $[7,8]$ which found that there was a reduction in disruptive behavior with the use of audiotaped stories.

The American Academy of Pediatric Dentistry (AAPD) recognizes nitrous oxide/oxygen inhalation as a safe and effective technique to reduce anxiety, produce analgesia, and enhance effective communication between a patient and health care provider.Indications for use of nitrous oxide/oxygen analgesia/anxiolysis include, a fearful, anxious, or obstreperous patient, certain patients with special health care needs, patient whose gag reflex interferes with dental care, patient for whom profound local anesthesia cannot be obtained, cooperative child undergoing a lengthy dental procedure. Since the process of nitrous oxide inhalation involves usage of a nasal hood/mask, the induction process can be anxiety provoking for young children as they are already anxious about undergoing the dental treatment. Hence in this study audio distraction methods are used to make this entire process less anxiety provoking more relaxing for the anxious child.

White noise used as an audio distraction technique in this study has the same amplitude or intensity, throughout the audible frequency range (20 to $20,000 \mathrm{Hertz}$ ). White noise is so named because it's analogous to white light, which is a mixture of all visible wavelengths of light. [5] Some examples of white noise are the sound of waves, beach sounds, heartbeat noise that is used to mimic that of the mother, instrumental lullabies,etc. White noise is actually used to make children sleep faster and better, hence in this study it was used only during the induction process and later removed during the actual treatment as conscious sedation requires the child to respond to and follow the operator's instructions.

Since children are unable to comprehend their preferred choice of music at this young age, usage of white noise as a distraction method is a good option as it is soothing and acceptable by all children.

Although the intergroup results found in this study were not statistically significant; (which may be due to the smaller sample size), it was found that white noise group helped in rendering better treatment as the children could respond to the operator's instructions and listen to the soothing music at the same time.

Venham'sbehavior rating scale was used in this study, this scale explored the use of 6-point cooperative behavioral scale also called uncooperative behavior rating scale. This 6-point scale has points anchored in objective, specific and readily observable behavior [9]. Venham et al pointed out that the scale is reliable and valid and provides internal level measurement. In this study, behavior of the child was assessed using this scale at the start of the induction process of nitrous oxide and 1 minute after induction.

This study involves a combination of two basic behaviour guidance techniques namely audio distraction and nitrous oxide inhalation. It is proved that integration of good behavioural techniques leads to better results and more efficient treatment.

\section{Conclusion}

Within limitations of the study, it was found that usage of white noise as an audio distraction method during the induction process of nitrous oxide sedation is a good option as it is soothing and acceptable by all children.

\section{References}

[1]. Prabhakar AR, Marwah N, Raju OS. A comparison between audio and audiovisual distraction techniques in managing anxious pediatric dental patients. J Indian SocPedodPrev Dent. 2007 Oct-Dec;25(4):177-82.Pubmed PMID: 18007104.

[2]. Marwah N, Prabhakar AR, Raju OS. Music distraction-its efficacy in management of anxious pediatric dental patients. J Indian SocPedodPrev Dent. 2005 Oct-Dec;23(4):168-70.Pubmed PMID: 16327136.

[3]. Al Zoubi L, Schmoeckel J, Mustafa Ali M, Splieth CH. Parental acceptance of advanced behaviour management techniques in paediatric dentistry in families with different cultural background. Eur Arch Paediatr Dent. 2021 Aug;22(4):707-713.Pubmed PMID: 33768499.

[4]. Stach DJ. Nitrous oxide sedation: understanding the benefits and risks. Am J Dent.. 1995 Feb 1;8(1):47-50.

[5]. Oliveira MJ. White Noise Analysis: An Introduction. Let Us Use White Noise. 2017: 1-36.

[6]. Corah NL, Gale EN, Illig SJ. The use of relaxation and distraction to reduce psychological stress during dental procedures. J Am Dent Assoc. 1979 Mar 1;98(3):390-4.

[7]. Ingersoll BD, Nash DA, Gamber C. The use of contingent audiotaped material with pediatric dental patients. J Am Dent Assoc. 1984 Nov;109(5):7179.Pubmed PMID: 6208228.

[8]. Stark LJ, Allen KD, Hurst M, Nash DA, Rigney B, Stokes TF. Distraction: Its utilization and efficacy with children undergoing dental treatment. J ApplBehav Anal. 1989 Sep;22(3):297-307.

[9]. Narayan VK, Samuel SR. Appropriateness of various behavior rating scales used in pediatric dentistry: A Review. J Int Oral Health. 2020;2: 112-7.

[10]. American Academy of Pediatric Dentistry. Behavior guidance for the pediatric dental patient. The Reference Manual of Pediatric Dentistry. Chicago, Ill.: American Academy of Pediatric Dentistry; 2020:292-310 